\title{
Upon Using of Plastics Layer in Light Multilayered Armor
}

\author{
CATALIN ADETU ${ }^{1 *}$, VASILE NASTASESCU ${ }^{2,3}$, ALINA ELENA ADETU ${ }^{3}$, \\ FLORIAN VLADULESCU ${ }^{4}$ \\ ${ }^{1}$ University Politehnica of Bucharest, Romania, 313 Splaiul Independentei, 060042, Bucharest, Romania \\ ${ }^{2}$ Technical Sciences Academy of Romania, 26 Dacia Blvd., 010413, Bucharest, Romania \\ ${ }^{3}$ Ferdinand I Military Technical Academy, 39-49 George Cosbuc Blvd., 050141, Bucharest, Romania \\ ${ }^{4}$ INAS SA, 37C Nicolae Romanescu Blvd., 200738, Craiova, Romania
}

\begin{abstract}
The concept of ballistic protection is a subject of great importance and is defined as representing all the capabilities of the military vehicle to withstand attacks, in order to ensure protection of the crew during the missions. The projectile-plate impact research must answer a series of questions on designer or fighter behalf, among which the most important would be whether the bullet penetrates or perforates and whether the velocity after the perforation ensures a lethal effect on the personnel. The current paper presents the numerical evaluation of the working together of aluminum layers with plastic materials in a multilayer structure with honeycomb core, on impact with a rigid projectile. Plastic materials have revolutionized many industries and they are increasingly used due to their main properties, low mass and high strength. The research included the use of plastics, the positioning within the panel and the study of the two constructive versions of the structure, with coupled and uncoupled layers. Post-processing model and interpretation of the results are offered and these could be enriched and customized for other situations, similar or less similar, implicitly, the method is provided, finding a quick answer to certain questions.
\end{abstract}

Keywords: ballistic protection, projectile-plate impact, honeycomb core multilayer plate, plastic materials

\section{Introduction}

The current ballistic protection systems are in a permanent development, by optimizing the materials, the protection structures and by discovering new materials, which will ensure the most efficient protection. Thus, the shield is considered to be the assembly of plates designed to provide protection against bullets, enemy projectiles or their sketches $[1,2]$.

The projectile-plate impact research must answer a series of questions on designer or fighter behalf, among which the most important would be whether the bullet penetrates or perforates and whether the velocity after the perforation ensures a lethal effect on the personnel [3-5].

Of course, the most accurate answer to the questions about the projectile-plate impact is given by experimental research, but we must not forget that numerical analysis can prepare the way for experimental investigation, leading to saving time and materials. If we add to this the wealth of information provided by modern methods of numerical analysis, we can appreciate that numerical research on the impact of projectile-plate is extremely useful and necessary [6-8].

The most common method of numerical analysis and simulation of the behavior of continuous environments is, without doubt, the finite elements method. This method has a wide range of uses, such as static or dynamic analysis, analysis of solid or fluid media (of all types), consideration of any type of applied tasks, the use of a wide range of material models, error control and more $[9,10]$.

This paper is part of an extensive study on the possibility of increasing the ballistic protection of helicopters. The goal is to produce and test a multilayer panel, which would have a mass as low as possible and, at the same time, to provide increased protection.

\footnotetext{
*email: c.adetu@yahoo.com
} 
The current paper presents the numerical evaluation of the answer of aluminum layers with plastic materials in a multilayer structure with honeycomb core, on impact with a rigid projectile. The research included the use of plastics, the positioning within the panel and the study of the two constructive versions of the structure, with coupled and uncoupled layers.

It is known that plastic materials have revolutionized many industries for a number of different reasons to include the fact that they resist environmental degradation over time, presents low mass and high strength, are generally safe for human beings, are economical and widely available, and are produced with a wide variety of material properties that allow adaptation to many different applications.

\section{Materials and methods}

The purpose of this paper is to evaluate the performance of a multilayer panel, in two constructive variant, consisting of different layers: steel plate, two aluminum plates united by an aluminum honeycomb core and a plastic plate at the bottom, on impact with a $7.62 \mathrm{~mm}$ rigid projectile and to compare it with a reference plate. A normal impact was considered, with a impact velocity of $500 \mathrm{~m} / \mathrm{s}$ and the analyses time of $1.0 \mathrm{e}-4 \mathrm{~s}$.

For the theoretical study, the layers of the structure had the following mechanical characteristics:

-Steel plate

-Density: $\rho=7865 \mathrm{~kg} / \mathrm{m}^{3}$

-Young's modulus: $\mathrm{E}=2.1 \mathrm{e} 11 \mathrm{~Pa}$

-Poisson's ratio: $v=0.27$

-Yield stress: $\sigma_{\mathrm{c}}=315 \mathrm{e} 6 \mathrm{~Pa}$

-Thickness $=0.01 \mathrm{~m}$

-Aluminum plate

-Density: $\rho=2700 \mathrm{~kg} / \mathrm{m}^{3}$

-Young's modulus: $\mathrm{E}=0.690 \mathrm{e} 11 \mathrm{~Pa}$

Poisson's ratio: $v=0.33$

-Yield stress: $\sigma_{\mathrm{c}}=315 \mathrm{e} 6 \mathrm{~Pa}$

-Thickness $=0.01 \mathrm{~m}$

-Plastic plate ( Nylon 6/10)

-Density: $\rho=1389 \mathrm{~kg} / \mathrm{m}^{3}$

-Young's modulus: $\mathrm{E}=8.27 \mathrm{e} 9 \mathrm{~Pa}$

-Poisson's ratio: $v=0.28$

-Yield stress: $\sigma_{\mathrm{c}}=139 \mathrm{e} 6 \mathrm{~Pa}$

-Thickness $=0.01 \mathrm{~m}$

For ease in comparing the results, the material model used for the panel was plastic kinematic hardening and a rigid material was considered for the bullet.

The position of the plastic layer is very important and has a special role in the structure. An analysis of the structure that will be presented was performed and it resulted that the positioning of the plastic material as the last layer is the best option in this case. Positioning as the last layer allows the plastic material to absorb impact shock from the very beginning and, at the same time, protects the crew against splinters.

For the plastic plate was considered Nylon 6/10, a plastic material that is used for a variety of applications which includes clothing, reinforcement in rubber material like car tires, for use as a rope or thread, and for a number of injection molded parts for vehicles and mechanical equipment. It is often used as a substitute for low strength metals in applications like car engines because of its high strength (relative to other plastics), high temperature resilience, and high chemical compatibility.

The two constructive variants of the honeycomb core multilayer panel are with unsolidated and solidated plates. The honeycomb core is the same for both variant and is presented in Figure 2. These two panel models, together with a reference model, consisting of a full plate (without core), will be compared, to see which of them has the best impact behavior. 
All the panels were simulated by finite element method and the nodes belonging to the four sides have all degrees of freedom blocked $(\mathrm{DOF}=0)$. Also, all the panels have the same material model and same dimensions $(0.095 \mathrm{~m}$ x $0.10 \mathrm{~m}$ x $0.009 \mathrm{~m})$, as can be seen in Figure 1.

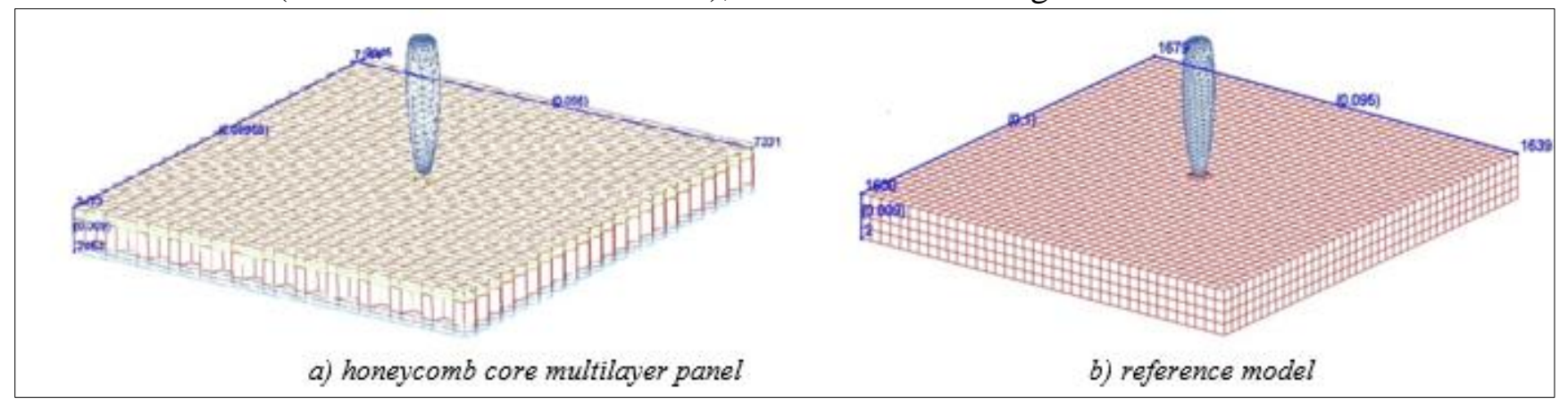

Figure 1. Dimensions of the panels

The structure of the honeycomb core multilayer plate is presented in Figure 2.

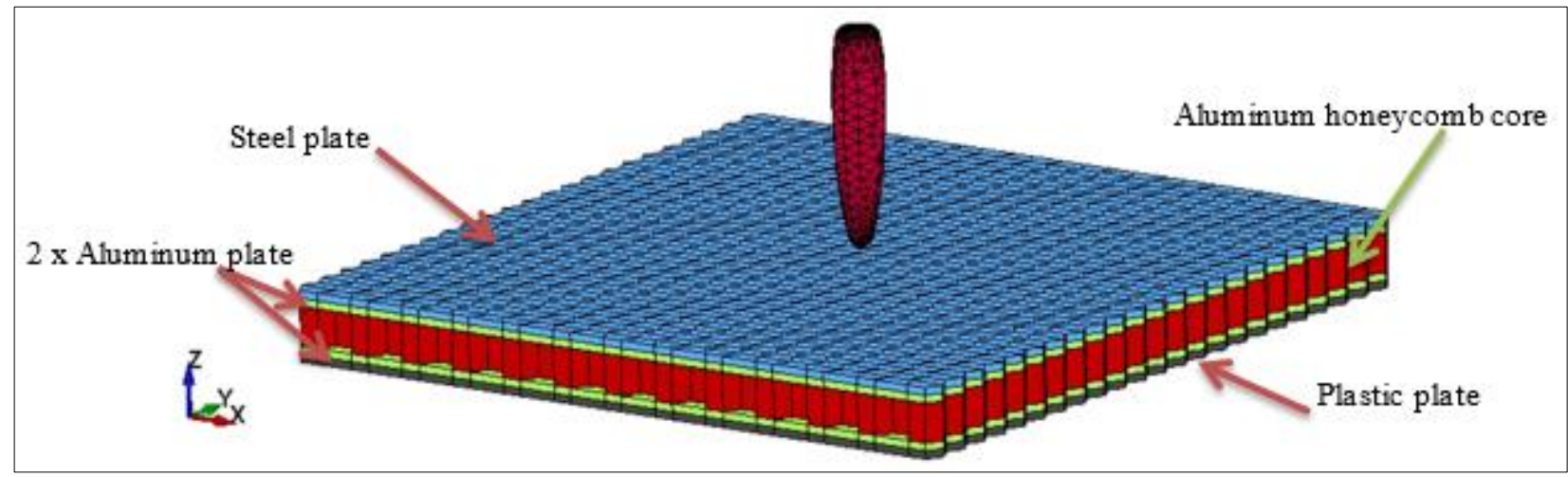

Figure 2. Honeycomb core multilayer plate

The honeycomb core (Figure 3) is the same for both constructive variants and its characteristics are the following:

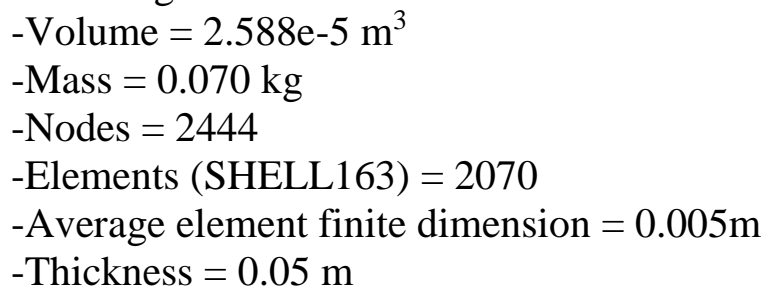

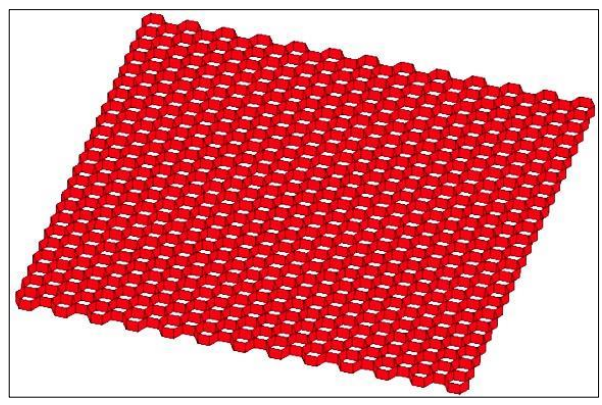

b)

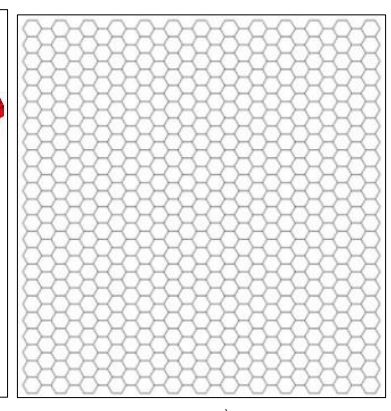

c)

Figure 3. The honeycomb core

The interest was focused on the plate, that's why it was considered a rigid material for the bullet. The 
using of these assumptions covers the calculation results and save computer time.

The characteristics of the bullet (Figure 4) are the following:

-Caliber $=7.62 \mathrm{~mm}$

-Density: $\rho=7850 \mathrm{~kg} / \mathrm{m}^{3}$

-Impact velocity $=500 \mathrm{~m} / \mathrm{s}$

-Volume $=6,8587 \mathrm{e}-7 \mathrm{~m}^{3}$

-Mass $=0.00538 \mathrm{~kg}$

-Elements $($ SOLID168) $=3860$

-Nodes $=6046$

-Average element finit dimension $=0.001 \mathrm{~m}$

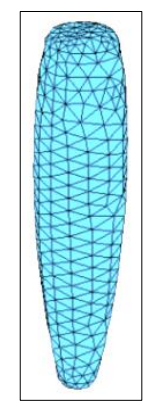

Figure 4. Finite

element model of the bullet

\subsection{Unsolidated (uncoupled) plates with honeycomb core}

A first variant of the structure consists of a honeycomb core multilayer panel with unsolidated plates. The projectile-panel impact was simulated by FEM as it is shown in Figure 2. The global characteristics of the honeycomb core multilayer panel with unsolidated plates are:

-Total volume $=6.3221 \mathrm{e}-5 \mathrm{~m}^{3}$

-Total mass $=0.20699 \mathrm{~kg}$

-Total elements $=8703$

-Total nodes $=11088$

In this constructive variant, all the panel components work independently, their behavior being strongly determined by the contact between them: the contact of the bullet with each of the elements and the contact between the layers (plate-plate-core-plate-plate).

In the Figure 5 it is shown the evolution of the impact, with its effects (deformation with perforation of the plate), by presenting the deformed state during the analysis of 80 microseconds.

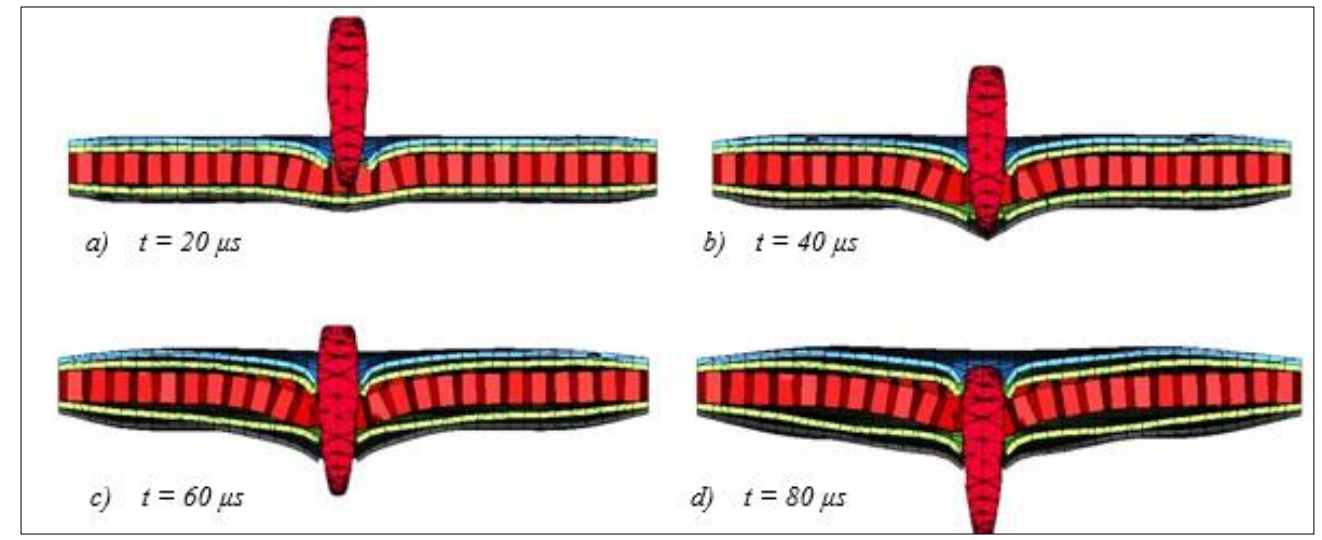

Figure 5. Time evolution of the impact

In the Figure 6 are presented, as post-processing, the values and appearance of the field of von Mises equivalent stresses for the multilayered plate at $\mathrm{t}=80 \mu \mathrm{s}$. 


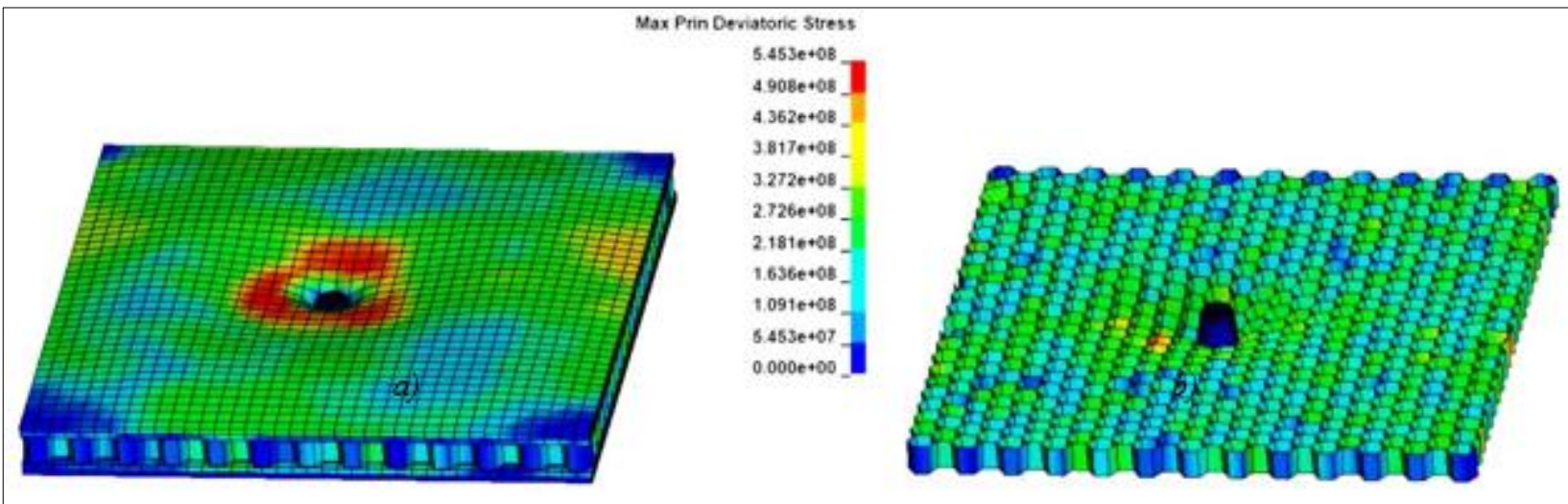

Figure 6. von Mises equivalent stresses at $\mathrm{t}=80 \mu \mathrm{s}$

The time evolution of the plate total energy on each component of the panel under impact with the projectile is presented in Figure 7. As it can be seen, the honeycomb core absorbs the most energy compared to other plates.

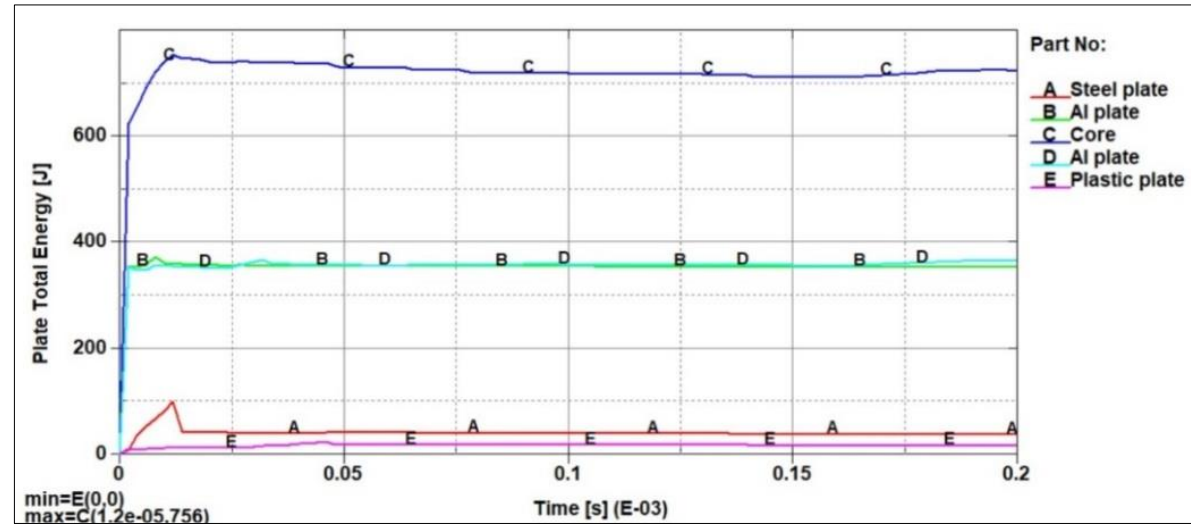

Figure 7. Time evolution of the plate total energy

Analyzing the allure of the curve in Figure 8, can be observed a constant level at the beginning of the diagram that represents the period elapsed to cover the initial bullet-plate distance. After that, as the Figure 8 shows, the evolution of the bullet speed is a nonlinear one, with jumps, and after panel perforation, the speed becomes constant. The evolution in jumps is caused by the different impact behavior of those five layers working together only by contact.

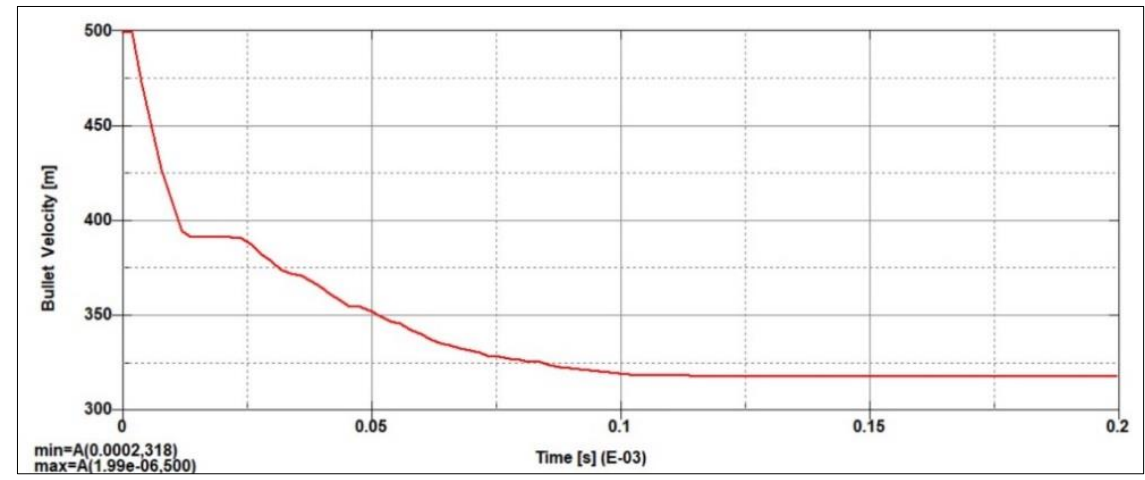

Figure 8. Time evolution of the bullet velocity

\subsection{Solidated (coupled) plates with honeycomb core}

Given that the honeycomb core multilayer panel presented above is a constructive variant with 
unsolidated plates, I will further present the constructive variant with solidated plates, shown in Figure 9, in order to observe the difference between these two constructive models. The global characteristics of the honeycomb core multilayer panel with solidated plates are:

\section{-Total volume $=6.3221 \mathrm{e}-5 \mathrm{~m}^{3}$ \\ -Total mass $=0.20699 \mathrm{~kg}$ \\ -Total elements $=8703$ \\ -Total nodes $=11088$}

The solidarity plates-honeycomb core consists in the coincidence of the nodes belonging to the plates with the honeycomb nodes. So, there is a perfect continuity of the material and of the working between finite elements belonging to panel components. Of course, a new plate mesh was adopted for each plate which can be seen in Figure 9.

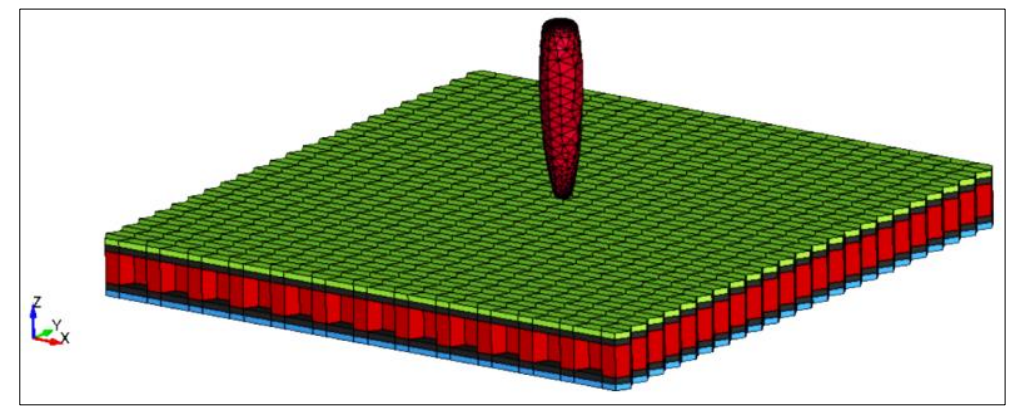

Figure 9. Finite element model of the panel

In the Figure 10 is shown the evolution of the impact during the analysis, for a period of 80 microseconds. For this case, same as the unsolidated plates, the bullet perforate the multilayer panel, but presents better performances on impact resistance.

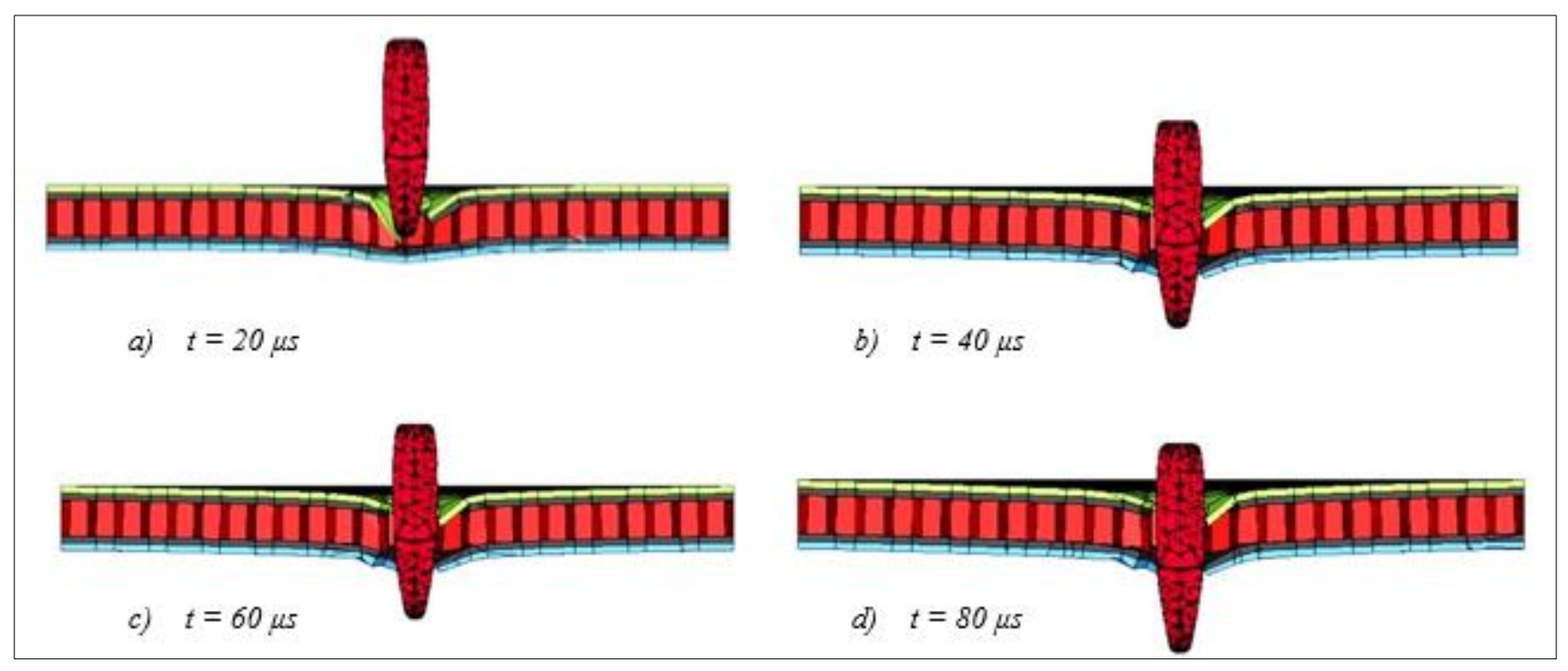

Figure 10. Time evolution of the impact

In the Figure 11, by post-processing, the values and the appearance of the field of von Mises equivalent stresses, for the coupled plates at $\mathrm{t}=40 \mu \mathrm{s}$ and $\mathrm{t}=80 \mu \mathrm{s}$ are presented. 


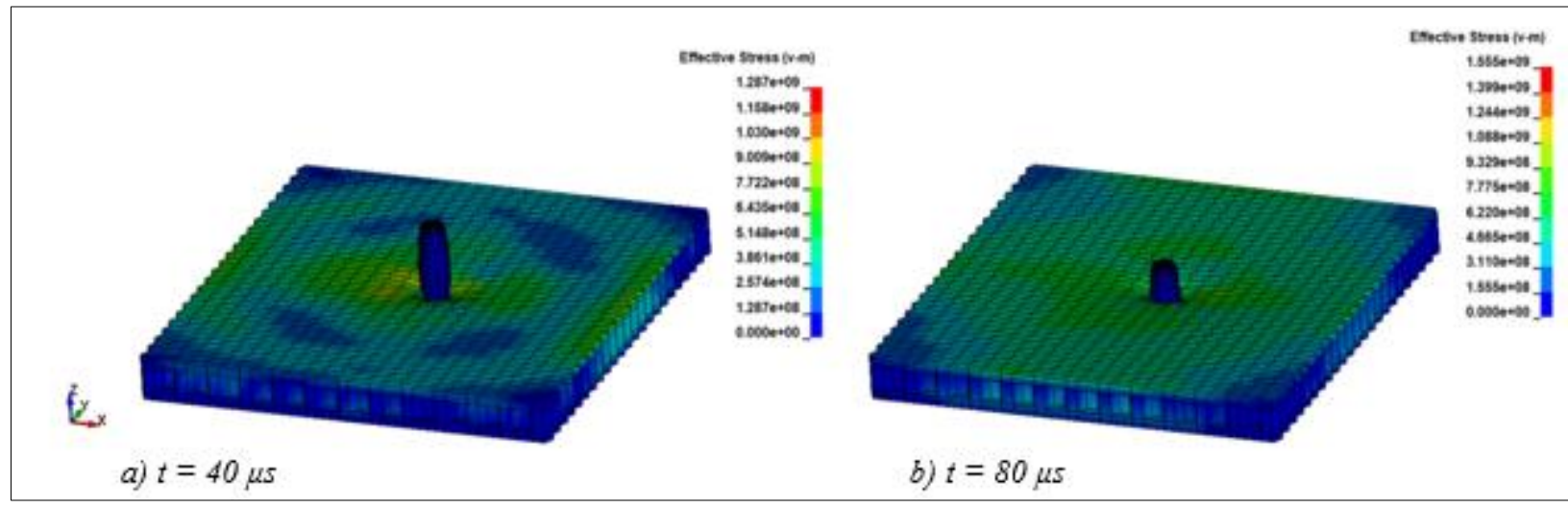

Figure 11. The von Mises equivalent stress field

The time evolution of the plate total energy on each component of the panel on impact with the projectile is presented in Figure 12. It can be seen that the steel plate absorb the most energy at the impact moment, after that, the honeycomb core absorb much more energy than the outer plates.

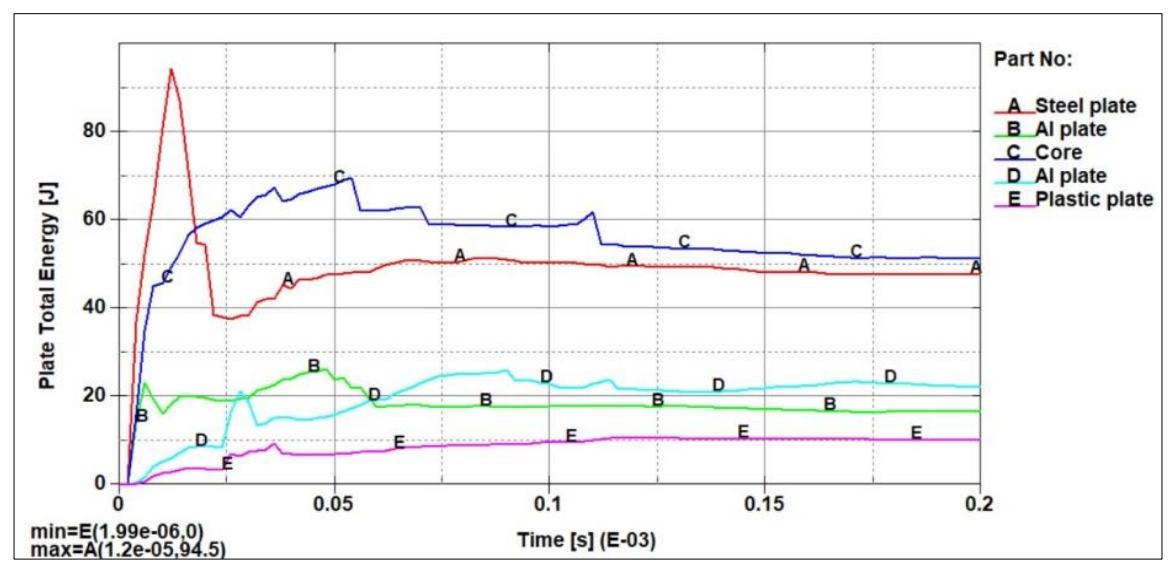

Figure 12. Time evolution of the plate total energy

In the Figure 13 is presented time evolution of the aluminum and plastic plate total energy. Can be observed the absorption capacity of the plastic material compared to that of the aluminum. Obviously, a thicker layer of plastic would be more beneficial, but in this study we went to the minimum comparable thickness.

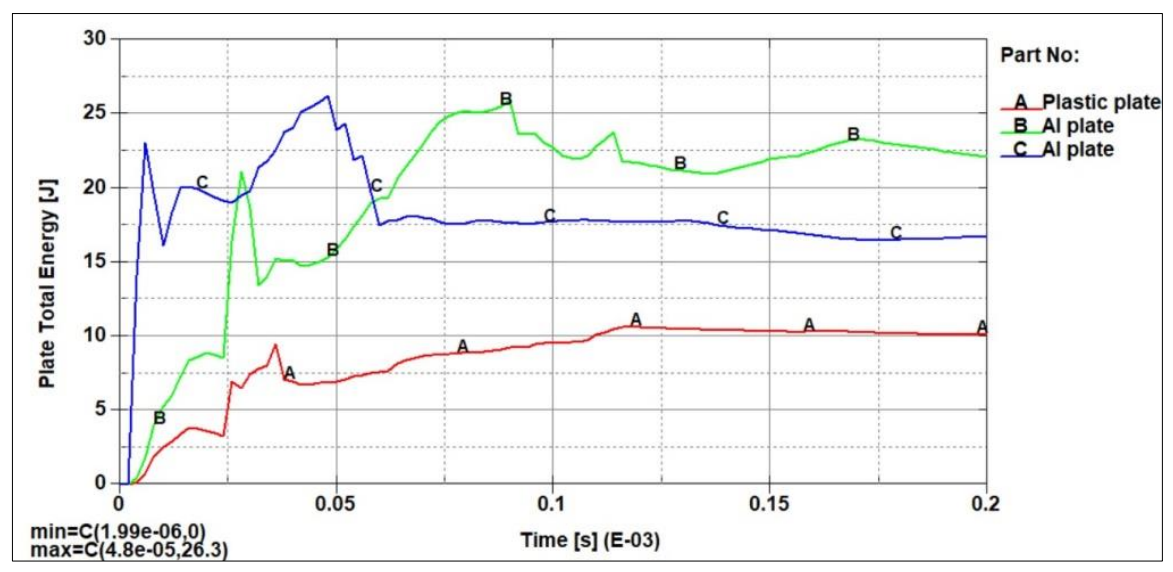

Figure 13. Time evolution of the $\mathrm{Al} \&$ plastic plate total energy 
Analyzing the allure of the curve in Figure 14, can be observed a constant level at the beginning of the diagram that represents the period elapsed to cover the initial bullet-plate distance. After that, as the Figure 15 shows, the evolution of the bullet speed is a nonlinear one, with jumps, and after panel perforation, the speed becomes constant. The evolution in jumps is caused by the different impact behavior of those five layers.

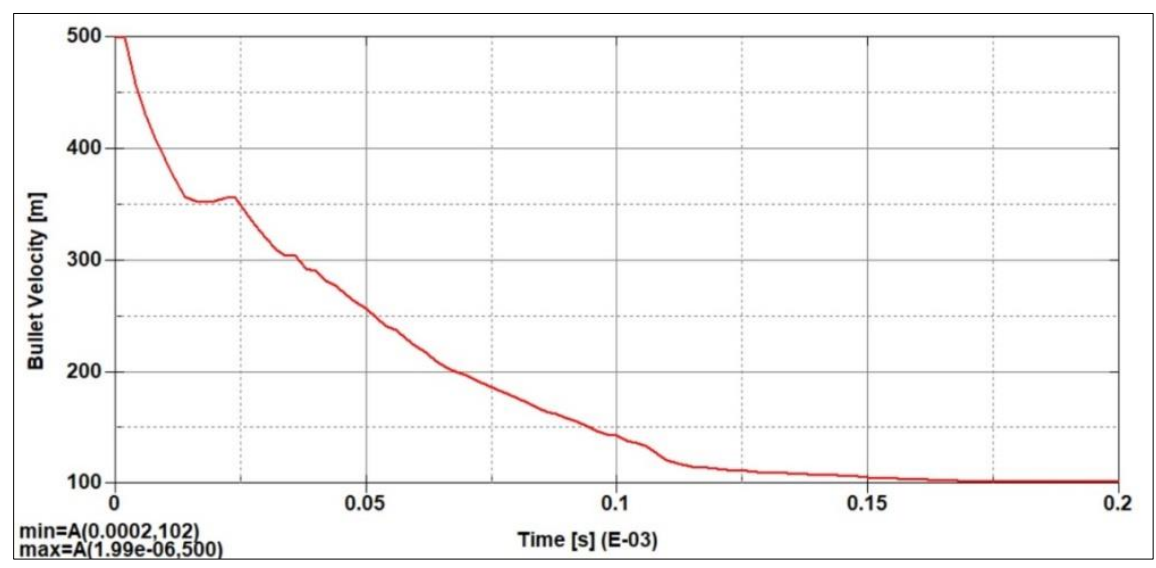

Figure 14. Time evolution of the bullet velocity

\subsection{Common plate without core}

In order to highlight the importance of the cellular core regarding the mass and material economy, I will further present a comparative analysis with a reference model, consisting of aluminum material, same dimension, only that the cell core will be full with material (a plate), as shown in Figure 15. The global characteristics of the common plate (reference model) are:

-Volume $=8.54998 \mathrm{e}-5 \mathrm{~m}^{3}$

-Mass $=0.2317 \mathrm{~kg}$

-Elements (SOLID164, brick with 8 nodes $)=6080$

-Nodes $=7995$

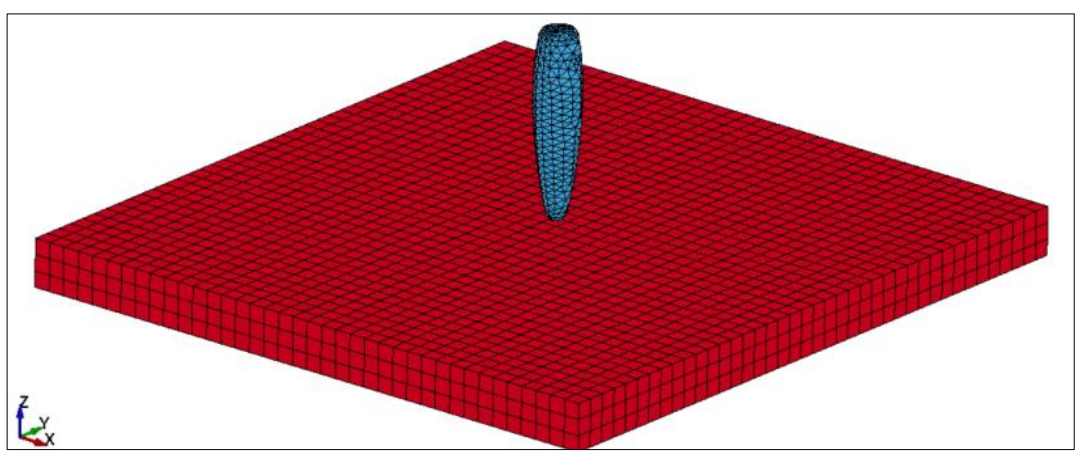

Figure 15. Reference model

In the Figure 16 are presented, as post-processing, the values and appearance of the field of von Mises equivalent stresses for the reference plate at $t=40 \mu \mathrm{s}$, top and bottom view. 


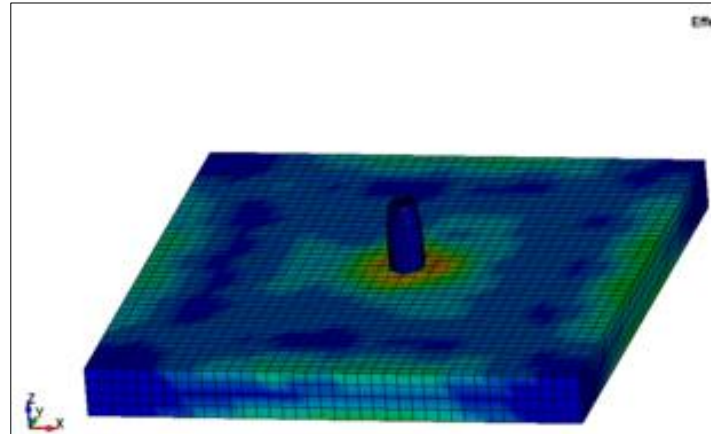

a) top view

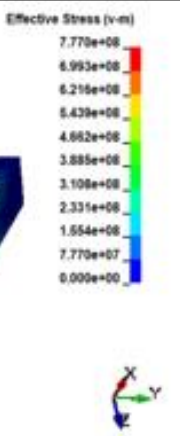

Figure 16. von Mises equivalent stresses at $\mathrm{t}=70 \mu \mathrm{s}$

In the Figure 17 can be observed that the reference plate absorbs a smaller energy than the honeycomb core multilayer panel, reaching a maximum energy of $150 \mathrm{~J}$.

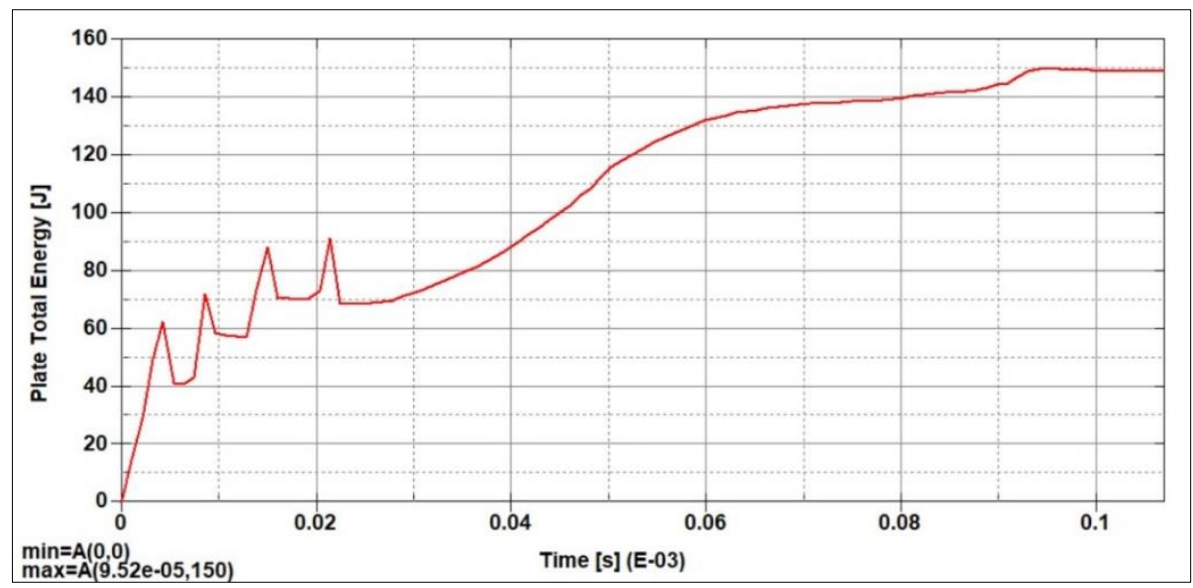

Figure 17. Time evolution of the plate total energy

Analyzing the allure of the curve in Figure 18, can be observed time evolution of the bullet velocity. After the perforation process, the bullet velocity is being reduced from the initial value of $500 \mathrm{~m} / \mathrm{s}$ to 305 $\mathrm{m} / \mathrm{s}$, when the bullet perforated the plate. At some point, it no longer meets resistance and it has a stabilized velocity of $389 \mathrm{~m} / \mathrm{s}$. The increase in bullet velocity after reaching a minimum is explained by the transfer of the plate elastic energy from the plate to the bullet.

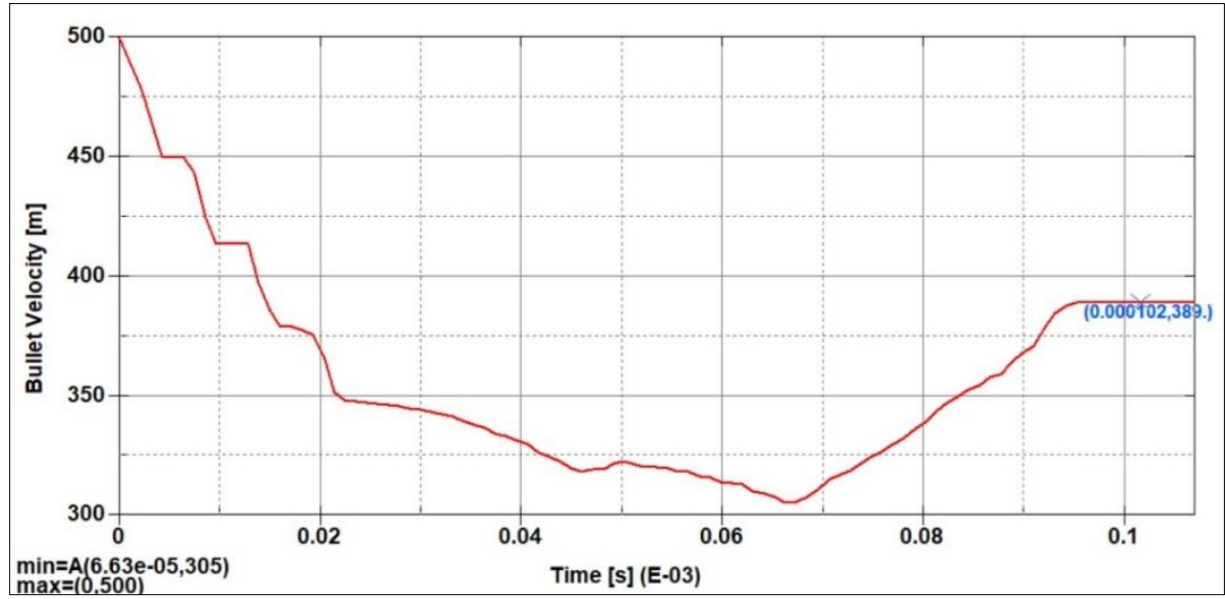

Figure 18. Time evolution of the bullet velocity 


\section{Results and discussions}

The results of the above study are synthetically presented in the Table 1 . It can be seen that, in similar conditions, the honeycomb multilayer panel with solidated plates presents the best behavior on impact, compared to the other two models.

Also, the honeycomb multilayer panel with unsolidated plates presents a better behavior on impact than the common plate without core.

Table 1. Comparison between the three models

\begin{tabular}{|c|c|c|c|}
\hline \multirow{2}{*}{$\frac{\text { Model }}{\text { Characteristics }}$} & \multicolumn{2}{|c|}{ Honeycomb multilayer panel } & \multirow{2}{*}{ Reference model } \\
\hline & Unsolidated plates & Solidated plates & \\
\hline Dimensions [m] & \multicolumn{3}{|c|}{$0.095 \mathrm{~m} \times 0.10 \mathrm{~m} \times 0.009 \mathrm{~m}$} \\
\hline Volume $\left[\mathrm{m}^{3}\right]$ & \multicolumn{2}{|c|}{$6.3221 \mathrm{e}-5$} & $6.65 e-5$ \\
\hline Mass [kg] & \multicolumn{2}{|c|}{0.20699} & 0.2317 \\
\hline Elements & \multicolumn{2}{|c|}{8703} & 6080 \\
\hline Nodes & \multicolumn{2}{|c|}{11088} & 7995 \\
\hline Impact velocity $[\mathrm{m} / \mathrm{s}]$ & \multicolumn{2}{|c|}{500} & 500 \\
\hline Remaining velocity $[\mathrm{m} / \mathrm{s}]$ & 318 & 102 & 389 \\
\hline$\Delta M_{\text {ref model }}$ (material economy) $[\mathrm{kg}]$ & \multicolumn{2}{|c|}{0.024} & - \\
\hline$\Delta M_{\text {ref model (material economy) [\%] }}$ & \multicolumn{2}{|c|}{9.37} & - \\
\hline $\begin{array}{l}\text { Economy } / \mathrm{m}^{2}[\mathrm{~kg}] \\
(0.009 \mathrm{~m} \text { thickness })\end{array}$ & \multicolumn{2}{|c|}{2.6} & - \\
\hline
\end{tabular}

In the case of the honeycomb multilayer panel with solidated plates, the remaining velocity of the bullet after impact is $102 \mathrm{~m} / \mathrm{s}$ and presents the best behavior. For the model with unsolidated plates, the remaining velocity of the bullet after impact is smaller than in the case of the reference model, which means that it offers better protection than this one.

An important aspect is represented by the positioning of the plastic layer. Positioning as the last layer allows the plastic to absorb the shock generated by the impact and, at the same time, protects the crew against splinters.

The best position, in terms of contribution to protection through this type of shield is highlighted by the analysis of the cooperation of the layers, in the two constructive variants. In the case of solidated plates, the remaining speed of the bullet is lower, hence the contribution of the plastic material.

As seen in Figure 13, the absorption capacity of the plastic material can be compared to that of the aluminum. Obviously, a thicker layer of plastic would be more beneficial, but in this study we went to the minimum comparable thickness.

Another important aspect represents the material economy. We have a material economy approximately of $10 \%$ when using the honeycomb core in construction of the panel. This material saving becomes very important in the context of using large panels, comparable to the floor of a helicopter.

A material saving means costs reduction and lower mass of the shield. If we talk about an industry of land forces, this material economy does not seem important, but if we refer to aviation industry, this economy is very important, because any extra payload matters.

\section{Conclusions}

Regarding the impact of the projectile-honeycomb core multilayer panel, presented in this paper, it can be seen that the honeycomb absorb a higher energy than the external plates. Of course, having the post-processing model available, it can be customized for different materials, especially composite materials, which are increasingly used for manufacturing shields, because they have a good resistance to breaking, physical-mechanical properties and other characteristics superior to metal alloys [11]. Their using has made it possible to achieve better configurations that meet the requirements for resistance to dynamic stresses, respectively, much lower specific mass and simpler technologies. Thus, composite materials can be a viable alternative when it is desired to provide a ballistic protection that is able to withstand multi-threats.

The most important thing that emerges from the presented study is the fact that, in the same 
conditions, the solidated plates presents a better behavior on impact in comparison with unsolidated plates.

Plastic materials have revolutionized many industries and they represents a new version to consider, especially for the properties they have: low weight and high strength. These properties were also observed in the case presented above, where we used nylon for the plastic plate.

Through the study and simulations presented in this paper, it should be noted that post-processing model and interpretation of results are offered and these could be enriched and customized for other situations, similar or less similar, implicitly, the method is provided, finding a quick answer to certain questions. Of course, the most accurate answer to the questions about the projectile-plate impact is given by experimental research, but we must not forget that numerical analysis can prepare the way for experimental investigation, leading to saving time and materials. If we add to this the wealth of information provided by modern methods of numerical analysis, we can appreciate that numerical research on the impact of projectile-plate is extremely useful and necessary. Also, can be noted that this paper opens a new field of use of plastics in ballistic protection and represents only a part of the extensive analysis of the use of plastics in the construction of light multilayer shields.

Acknowledgments: This work is supported by the project ANTREPRENORDOC, in the framework of Human Resources Development Operational Program 2014-2020, financed from the European Social Fund under the contract number 36355/23.05.2019 HRD OP /380/6/13 - SMIS Code: 123847

\section{References}

1. CHERECHEŞ, T., BUNEA, M., BUCNARU, G., Muniţii. Cartea întâi, Editura Academia Tehnică Militară, Bucureşti, 1996 (in Romanian).

2. HOU, W., ZHU, F., LU, G., \& FANG, D. N., Ballistic impact experiments of metallic sandwich panels with aluminium foam core. International journal of impact engineering, 37(10), pp. 1045-1055.

3. CORMOŞ, R., PETRESCU, H.-A., HADĂR, A., ADÎR, G.M., GHEORGHIU, H., "Finite Element Analysis of the Multilayered Honeycomb material Subjected to Impact Loading", Mater. Plast., 54(1), 2017, 180-185.

4. BUCUR, F., TRANA, E., \& ROTARIU, A., Numerical and Experimental Study on the Locally Blast Loaded Polyurea Coated Steel Plates, Mater. Plast., 56(3), 492-499.

5. PETRESCU, H.-A., HADĂR, A., PASTRAMĂ, S.D., Experimental Program for Impact Tests on a Honeycomb Core Composite Material, Proceedings of The Romanian Academy, Series A - Mathematics Physics Technical Sciences Information Science, Vol. 18, Number 2/2017, pp. 150-157.

6. NĂSTĂSESCU V., BÂRSAN GH., Metoda particulelor libere în analiza numerică a mediilor continue, Editura AGIR, Bucureşti, 2015 (in Romanian).

7. HADĂR, A., NICA, M.N., CONSTANTINESCU, I.N., PASTRAMĂ, S.D., The Constructive and Geometric Optimization of the Junctions in the Structures Made from Laminated Composite Materials", Strojniski Vestnik - Journal of Mechanical Engineering, Vol. 52, No. 7-8/06, Jul-Aug. 2006, Ljubljana, pp. 546-551.

8. NĂSTĂSESCU V., BÂRSAN GH., Metoda elementelor libere Galerkin în analiza structurilor, Editura Academiei Romane, Bucureşti, 2018 (in Romanian).

9. SOROHAN, ŞT., CONSTANTINESCU, I. N., Practica modelării şi analizei cu elemente finite, Bucureşti, 2003 (in Romanian).

10. DRĂGHICI, S., PETRESCU, H.-A., JIGA, G., HADĂR, A., TUDOSE, V., BUCUR, D.M., TUDOSE, D.I., A Different Approach for Obtaining the Shear Moduli of a Composite Material, Rev. Chim., 70(12), 2019, 4470-4476.

11. HADĂR, A., Structuri din compozite stratificate, Editura Academiei şi Editura AGIR, Bucureşti, 2002.

Manuscript received: 22.06 .2020 